\title{
Equatorial plasma bubbles and L-band scintillations in Africa during solar minimum
}

\author{
V. V. Paznukhov ${ }^{1}$, C. S. Carrano ${ }^{1}$, P. H. Doherty ${ }^{1}$, K. M. Groves ${ }^{2, *}$, R. G. Caton ${ }^{2}$, C. E. Valladares ${ }^{1}$, G. K. Seemala ${ }^{1}$, \\ C. T. Bridgwood ${ }^{1}$, J. Adeniyi ${ }^{3}$, L. L. N. Amaeshi ${ }^{4}$, B. Damtie ${ }^{5}$, F. D'Ujanga Mutonyi ${ }^{6}$, J. O. H. Ndeda ${ }^{7}$, P. Baki ${ }^{8}$, \\ O. K. Obrou ${ }^{9}$, B. Okere ${ }^{10}$, and G. M. Tsidu ${ }^{11}$ \\ ${ }^{1}$ Institute for Scientific Research, Boston College, Chestnut Hill, MA, USA \\ ${ }^{2}$ Air Force Research Laboratory, Hanscom Field, MA, USA \\ ${ }^{3}$ University of Ilorin, Ilorin, Nigeria \\ ${ }^{4}$ University of Lagos, Lagos, Nigeria \\ ${ }^{5}$ Bahir Dar University, Bahir Dar, Ethiopia \\ ${ }^{6}$ Makerere University, Kampala, Uganda \\ ${ }^{7}$ Jomo Kenyatta University, Nairobi, Kenya \\ ${ }^{8}$ University of Nairobi, Nairobi, Kenya \\ ${ }^{9}$ Université de Cocody à Abidjan, Abidjan, Cote d'Ivoire \\ ${ }^{10}$ University of Nigeria, Nsukka, Nigeria \\ ${ }^{11}$ Addis Ababa University, Addis Ababa, Ethiopia \\ * now at: Institute for Scientific Research, Boston College, Chestnut Hill, MA, USA
}

Correspondence to: V. V. Paznukhov (vadym.paznukhov@bc.edu)

Received: 30 September 2011 - Revised: 24 February 2012 - Accepted: 6 March 2012 - Published: 16 April 2012

\begin{abstract}
We report on the longitudinal, local time and seasonal occurrence of equatorial plasma bubbles (EPBs) and L band (GPS) scintillations over equatorial Africa. The measurements were made in 2010, as a first step toward establishing the climatology of ionospheric irregularities over Africa. The scintillation intensity is obtained by measuring the standard deviation of normalized GPS signal power. The EPBs are detected using an automated technique, where spectral analysis is used to extract and identify EPB events from the GPS TEC measurements.

Overall, the observed seasonal climatology of the EPBs as well as GPS scintillations in equatorial Africa is adequately explained by geometric arguments, i.e., by the alignment of the solar terminator and local geomagnetic field, or STBA hypothesis (Tsunoda, 1985, 2010a). While plasma bubbles and scintillations are primarily observed during equinoctial periods, there are longitudinal differences in their seasonal occurrence statistics. The Atlantic sector has the most intense, longest lasting, and highest scintillation occurrence rate in-season. There is also a pronounced increase in the EPB occurrence rate during the June solstice moving west to east. In Africa, the seasonal occurrence shifts towards boreal summer solstice, with fewer occurrences and shorter durations in equinox seasons. Our results also suggest that the
\end{abstract}

occurrence of plasma bubbles and GPS scintillations over Africa are well correlated, with scintillation intensity depending on depletion depth. A question remains about the possible physical mechanisms responsible for the difference in the occurrence phenomenology of EPBs and GPS scintillations between different regions in equatorial Africa.

Keywords. Ionosphere (Equatorial ionosphere; Ionospheric irregularities) - Radio science (Space and satellite communication)

\section{Introduction}

Plasma interchange instabilities present in the equatorial ionosphere after sunset generate large-scale depletions in the ambient electron density. These bubbles of depleted plasma, which are commonly referred to as equatorial plasma bubbles (EPB), rise vertically and then drift for up to several hours. The presence of plasma irregularities with a wide range of scales (from $10 \mathrm{~cm}$ to $1000 \mathrm{~km}$ ) within these depletions disrupts communications and navigation systems in a broad latitudinal band ( \pm 20 degrees) surrounding the geomagnetic equator by scattering radio wave signals that pass through 


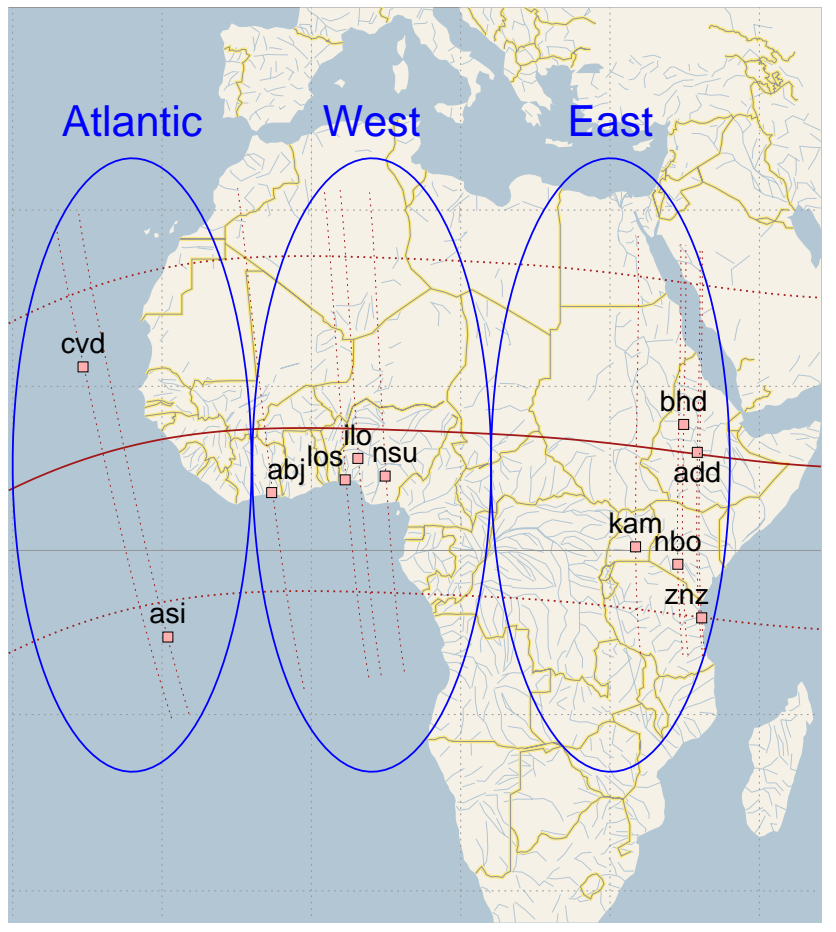

Fig. 1. SCINDA station locations in equatorial Africa. The geomagnetic field configuration is shown as well; the solid curve indicates the dip equator, the horizontal dotted curves indicate \pm 20 degree dip latitudes, and the dotted vertical curves show the magnetic meridians through the stations. Three geographical regions (Atlantic, West, and East) can be introduced using the existing stations.

them. These turbulent ionospheric conditions were given a name "spread-F" primarily because of the way they affect the $\mathrm{F}$ layer trace in ionograms, by producing spreading in the echo range and frequency. Although other mechanisms besides equatorial spread $\mathrm{F}$ (ESF) can produce equatorial scintillation (for example, bottomside spread F or BSSF (Valladares et al., 1983)), the scintillations from ESF are likely to have the strongest impact on operational systems (Whalen, 2000). Radio wave signals that propagate through ESF irregularities experience random scattering and diffraction, resulting in random fluctuations in signal amplitude and phase referred to as scintillations. Scintillations due to ionospheric disturbances are known to degrade and disrupt satellite-based communications and navigation systems (Datta-Barua et al., 2010; Carrano and Groves, 2010); this is why the study of their physics and climatology is an active research topic in ionospheric physics.

The EPB/ESF phenomena and the associated GPS scintillations have been studied intensively from 1960s both theoretically and experimentally (e.g., Calvert and Cohen, 1961; Farley et al., 1970; Woodman and La Hoz, 1976; McClure et al., 1998; Hysell and Kudeki, 2004; Abdu et al., 2009; Tsunoda, 2010b). Several models, climatological (Secan et al., 1995) as well as first-principle (Retterer and Gentile, 2009)
Table 1. SCINDA station locations in Africa. Station dip angles are calculated using IGRF model for the altitude of $350 \mathrm{~km}$.

\begin{tabular}{lccrc}
\hline Station name & Geo Lat & Geo Lon & Dip angle & Abbreviation \\
\hline Abidjan, Ivory Coast & $5.3^{\circ} \mathrm{N}$ & $4.0^{\circ} \mathrm{W}$ & $-14.2^{\circ}$ & abj \\
Addis Ababa & $9.0^{\circ} \mathrm{N}$ & $38.8^{\circ} \mathrm{E}$ & $2.2^{\circ}$ & add \\
Ascension Island & $8.0^{\circ} \mathrm{S}$ & $14.4^{\circ} \mathrm{W}$ & $-38.7^{\circ}$ & asi \\
Bahir Dar, Ethiopia & $11.6^{\circ} \mathrm{N}$ & $37.4^{\circ} \mathrm{E}$ & $8.1^{\circ}$ & bhd \\
Cape Verde & $16.7^{\circ} \mathrm{N}$ & $23.0^{\circ} \mathrm{W}$ & $16.9^{\circ}$ & cvd \\
Ilorin, Nigeria & $8.5^{\circ} \mathrm{N}$ & $4.7^{\circ} \mathrm{E}$ & $-6.3^{\circ}$ & ilo \\
Kampala, Uganda & $0.3^{\circ} \mathrm{N}$ & $32.6^{\circ} \mathrm{E}$ & $-20.6^{\circ}$ & kam \\
Lagos, Nigeria & $6.5^{\circ} \mathrm{N}$ & $3.4^{\circ} \mathrm{E}$ & $-11.3^{\circ}$ & los \\
Nairobi, Kenya & $1.3^{\circ} \mathrm{S}$ & $36.8^{\circ} \mathrm{E}$ & $-22.9^{\circ}$ & nbo \\
Nsukka, Nigeria & $6.9^{\circ} \mathrm{N}$ & $7.4^{\circ} \mathrm{E}$ & $-10.1^{\circ}$ & nsu \\
Zanzibar, Tanzania & $6.2^{\circ} \mathrm{S}$ & $39.2^{\circ} \mathrm{E}$ & $-32.6^{\circ}$ & znz \\
\hline
\end{tabular}

have been proposed to describe the occurrence and variability of the ESF, EPBs, and GPS scintillations. It is typically assumed (e.g., McClure et al., 1998) that two major factors are responsible for the spread-F occurrence: variations in the linear growth rate of the generalized Rayleigh-Taylor instability (e.g., Sultan, 1996) and the presence of the seed perturbation (e.g., Hysell et al., 1990). The first factor is mainly controlled by the ionospheric electrodynamics, while the seeding perturbations are typically attributed to the presence of medium scale gravity waves (e.g., Tsunoda, 2010b). The relative importance of the two factors is still a subject of a debate. It is known that ESF typically occur within \pm 20 degrees of geomagnetic equator, but the overall climatology of the ESF occurrence is quite complex. The phenomenon exhibits significant variations in longitude, season and local time (Aarons, 1993). The majority of the observed ESF, however, occur during the equinox seasons after the sunset. Tsunoda (2010a) introduced a hypothesis that the global climatology of the ESF occurrence can be best explained by the condition of the solar terminator alignment along the local geomagnetic field (STBA hypothesis). Overall, this idea explains the observed ESF occurrence reasonably well, although certain discrepancies with observations, especially during the solstices, still exist (e.g., Burke et al., 2004; Gentile et al., 2006).

The overwhelming majority of the observations of ESF and GPS scintillations to date have been made in the South American region, while other regions of the Earth, including the African continent have been left largely unexplored due to the absence of routine ground based ionospheric observations in these parts of the world. Recently, there have been some EPB studies using satellite observations (Huang et al., 2002; Hei et al., 2005; Stolle et al., 2006; Gentile et al., 2006) but the data available was often scarce, and in some studies measurements were made in the topside ionosphere only. Wiens et al. (2006) reported results of observations of EPBs and GPS scintillations in Eritrea, but their study was limited to a local region in East Africa. In this work we present some of the first results of EPB and GPS scintillations observations made in 2010 throughout the equatorial Africa region. 


\section{Data collection}

Sponsored in part by the International Heliophysical Year (IHY) program, Boston College, Air Force Research Laboratory (AFRL), and several universities in Africa have collaborated to deploy a network of GPS receivers throughout equatorial Africa, a region which has been largely devoid of ground-based ionospheric monitoring instruments. High data-rate NovAtel GSV4004B GPS receivers capable of measuring Total Electron Content (TEC) and GPS scintillations were installed at 10 new locations near the geomagnetic equator, with the stations positions summarized in Table 1 and illustrated with Fig. 1.

Most of the above stations started operations in 2009, except the Cape Verde station which began operations in 2006, and the Ascension Island station which had been in operation much earlier. All these stations routinely collect GPS data and the results of the measurements (S4 index and GPS TEC calculations) are stored in the Scintillation Network Decision Aid (SCINDA) database (Groves et al., 1997). Unfortunately, in 2010 there was still a large gap in the central Africa not covered by the GPS receiver network. As of 2011 there have been three more stations installed in the Central African region, near the geomagnetic equator (Congo). At present there are several other GPS TEC receiver sites in equatorial Africa region operating continuously, however in this study we limited our data analysis to the SCINDA stations that provided simultaneous S4 index measurements.

Figure 2 shows an example of the GPS record from Cape Verde station. The top panel shows vertical TEC and satellite elevation angle as a function of time. The bottom panel displays the $\mathrm{S} 4$ index for the same time interval calculated using same satellite transmissions. The scintillation intensity is obtained by measuring the standard deviation of normalized GPS signal power. In the given example, a clear TEC depletion is present at 02:00-03:00 UT causing associated GPS scintillations visible in the bottom panel. In order to automate the search for the TEC depletions (which are a manifestation of EPBs) we made use of the automated algorithm developed by Seemala and Valladares (2011). The algorithm is based on the spectral analysis of the GPS TEC records, and the plasma bubbles (depletions) are identified by amplitude thresholding of the digitally filtered data records. The filters used in the processing select time periods of 3-40 min and 25-120 min, corresponding to the typical durations of the EPBs. This processing has been shown to be very successful for the analysis of the data from the Low-Latitude Ionosphere Sensor Network (LISN) network of GPS receivers in South America (Valladares and Doherty, 2009). In Fig. 2, the square box in the top panel indicates the depletion which was found automatically by the Seemala-Valladares algorithm. The depth of the depletion is calculated as a difference between the background TEC value (at the time of depletion) and the TEC value at the minimum point of the depletion. In the shown example the

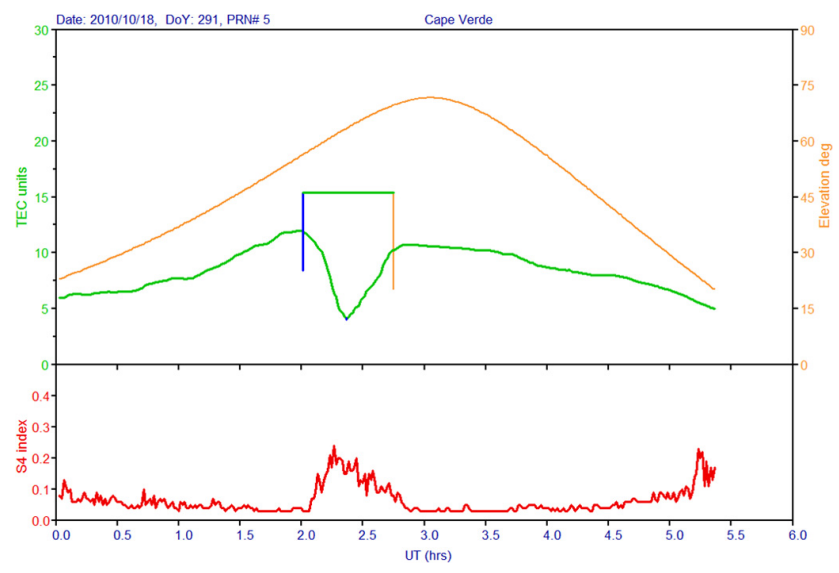

Fig. 2. Example of the measurements at Cape Verde (18 October 2010). The top plot shows the TEC measurements and also the elevation angle of the satellite. Bottom plot shows S4 index measurements at same location. In this example the depletion depth is about 7 TECU.

observed depletion depth was 7 TECU. Note that in Fig. 2, bottom panel, a short GPS scintillation is present at about 5.25 UT, corresponding to low elevation angle of the satellite ( $<30$ degrees). This signature is typically caused by the focusing and defocusing of the GPS signals reflected from terrestrial objects commonly referred to as "multipath" interference (Carrano and Groves, 2006). These signals have to be eliminated from further processing, which is partially accomplished by eliminating data records corresponding to low elevation angles.

Figure 3 shows a summary of the $\mathrm{S} 4$ index measurements made during 2010 at three equatorial stations: Cape Verde, Lagos and Kampala, which represent the Atlantic, West and East African sectors respectively. The year 2010 was still a period of very low solar activity: the F10.7 solar flux was around $80 \mathrm{sfu}\left(10^{-22} \mathrm{~W} \mathrm{~m}^{-2} \mathrm{~Hz}^{-1}\right)$ during the year. The $\mathrm{S} 4$ index data shown in the plot is computed over $1 \mathrm{~min}$ intervals. Overall, the observed GPS scintillations during this year of very low solar activity were rather weak, (e.g., scintillations with the S4 index value greater than 0.25 were rarely recorded). Under these conditions, the frequent presence of "multipath" interference signals presented a significant challenge to data analysis. To eliminate those signals, we first removed the data corresponding to low elevation angles ( $<30$ degrees) and then using the fact that the interferers had a daily periodicity (due to the $12 \mathrm{~h}$ orbits of the GPS satellites), we applied 2-D Fourier filtering to further suppress them. Some very slight traces of the "multipath" signals appearing in the yearly plots as stripes can be seen in the figure.

It is evident from the data shown in Fig. 3 that in all three sectors during the measurements in 2010 the scintillations were predominantly observed during the equinoctial seasons. However, the seasonal periods during which the scintillations were detected are longer for the African regions, where 

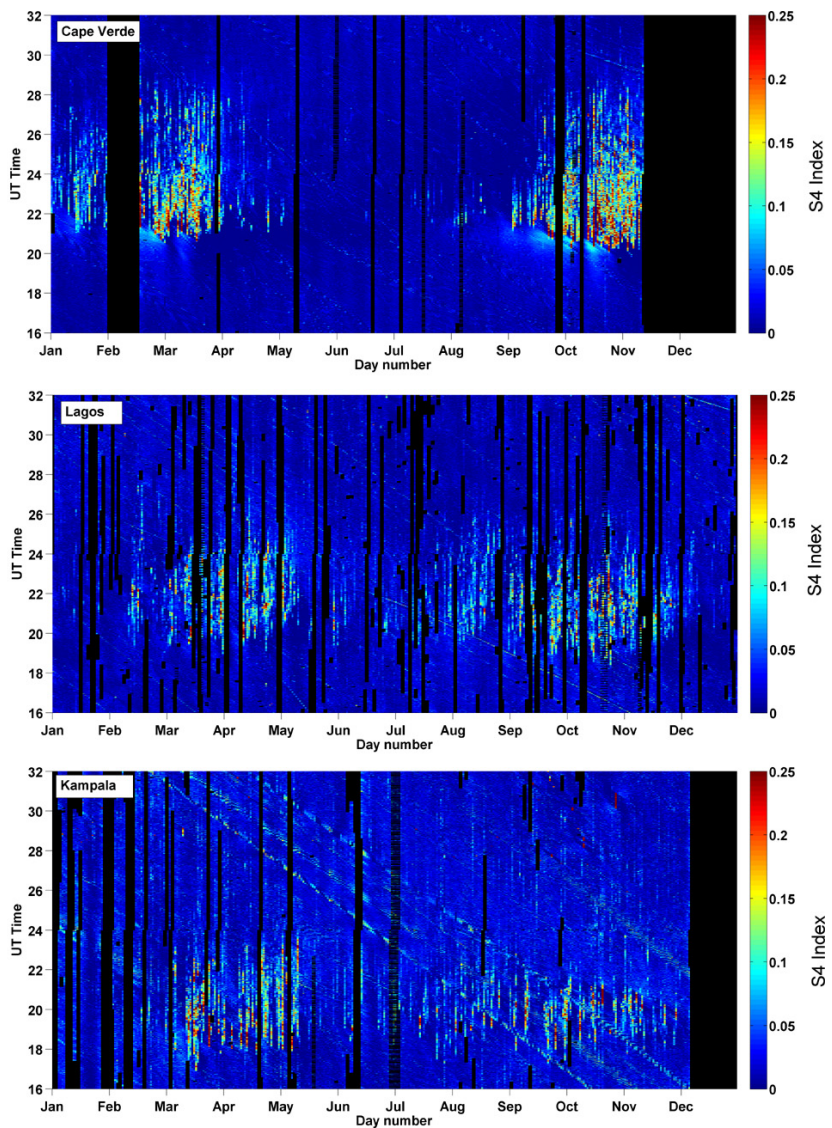

Fig. 3. Example of GPS scintillation data for the year 2010 from three regions: Cape Verde, Lagos, and Kampala. The graphs show distribution of the S4 index measurements as function of day of the season and universal time. Black color has been used to indicate missing data.

even in July a significant number of scintillations was observed. The Atlantic sector (Cape Verde station) observed the strongest and longest scintillations during the equinoctial seasons. Interestingly, the scintillations observed at Cape Verde were much more frequent and longer lasting than those at Ascension Island station (not shown). This should probably be attributed to the difference in the geomagnetic latitudes (dip angles) between the two Atlantic stations. The Ascension Island station is significantly further away from the magnetic equator, and therefore the plasma bubbles causing the scintillations seldom rise high enough during solar minimum to reach the magnetic flux tubes corresponding to the station location.

The next section presents more detailed climatological patterns of GPS scintillations and EPBs distributions over equatorial Africa by presenting the data from all stations as a function of season and geographical longitude.

\section{Results and discussion}

Figure 4 shows GPS scintillation summary plots presenting scintillation intensity (left) and scintillation occurrence rate (right). The data presented have been limited to elevation angles above 30 degrees and further filtered with 2-D Fourier to suppress the "multipath" interference signals as discussed above. The black solid lines indicate the locations where the angle between the solar terminator and local geomagnetic meridian is zero. Black dashed lines indicate regions where this angle is equal to 15 degrees. The occurrence rate of the GPS scintillations was calculated as a ratio of the number of days when at least one scintillation event (with S4 index value greater than 0.2 ) was observed to the total number of days of observations in each databin. These databins have a length of 5 days and a width of 5 degrees of longitude. The minimum duration of a single scintillation event was set at $15 \mathrm{~min}$. The white areas on the right plot represent the regions which were not covered by the observations in 2010 .

The strongest and most frequent scintillations were observed during equinoctial seasons in the Atlantic region. Scintillations in the West and East African sectors were noticeably weaker. However, in West and East Africa a few weak scintillations were also observed during the boreal summer time. Overall, however, during the solstices the number of the observed scintillations statistically is not very significant. In general, the occurrence of the GPS scintillations is in a good agreement with the Tsunoda's STBA hypothesis, i.e., the scintillations are most frequently observed during the time when the alignment of the solar terminator with the geomagnetic meridian is best. The significant difference in the intensities of the scintillations in Atlantic and African sectors is not explained by the STBA hypothesis, however, and remains an open question.

It is interesting to compare the observed climatology of the GPS scintillations to the occurrence pattern of the equatorial plasma bubbles in the equatorial African region. In our study the EPBs were detected from the routine GPS TEC measurements at the SCINDA stations, using a spectral analysis-based technique from (Seemala and Valladares, 2011) as was described in the previous section. The climatology of the EPBs is shown in Fig. 5, which is prepared in the same format as that of Fig. 4. Overall, the climatology of the EPBs is very similar to that of the GPS scintillations (Fig. 4), and therefore, also follows the STBA hypothesis, however, we note that there was a significant amount of EPBs detected during the boreal summer months, especially in West and East Africa. The SCINDA receivers typically did not measure scintillations associated with these boreal summer EPB, perhaps because the TEC depletion depth was relatively small.

Results shown in Fig. 5 are in agreement with the EPBs observations by the DMSP satellite reported by Gentile et al. (2006) who also observed a significant number of EPBs during June-July in the longitude range of $0-40$ degrees. The 

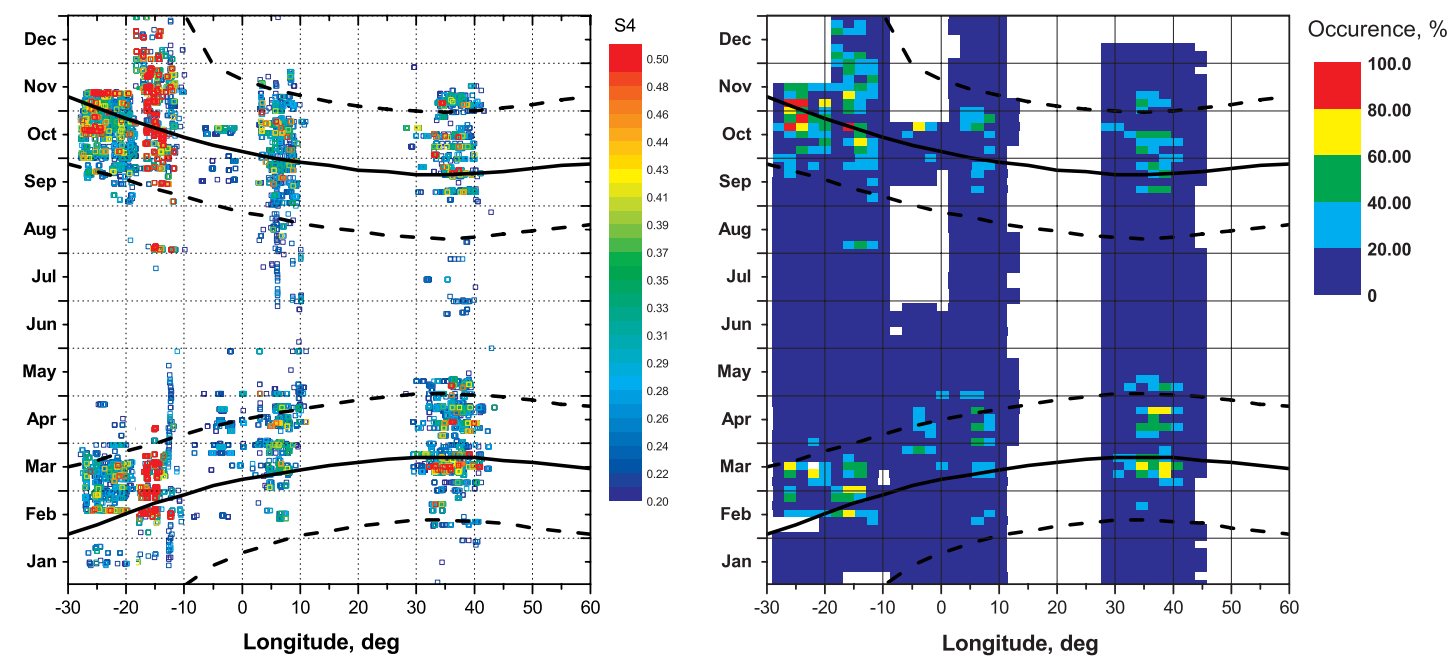

Fig. 4. Left panel: Scintillation intensity as a function of day of the year and longitude. Right panel: Scintillation occurrence rate. On the left panel individual S4 index measurements are shown, while on the right panel, data are binned in 5 degrees $\times 5$ day blocks, for which the occurrence rate is calculated. Black solid lines indicate the region where the solar terminator is aligned with the local geomagnetic field. Black dashed lines indicate regions where this angle is equal to 15 degrees. The strongest and most frequent scintillations occur in the Atlantic region during equinoctial seasons.
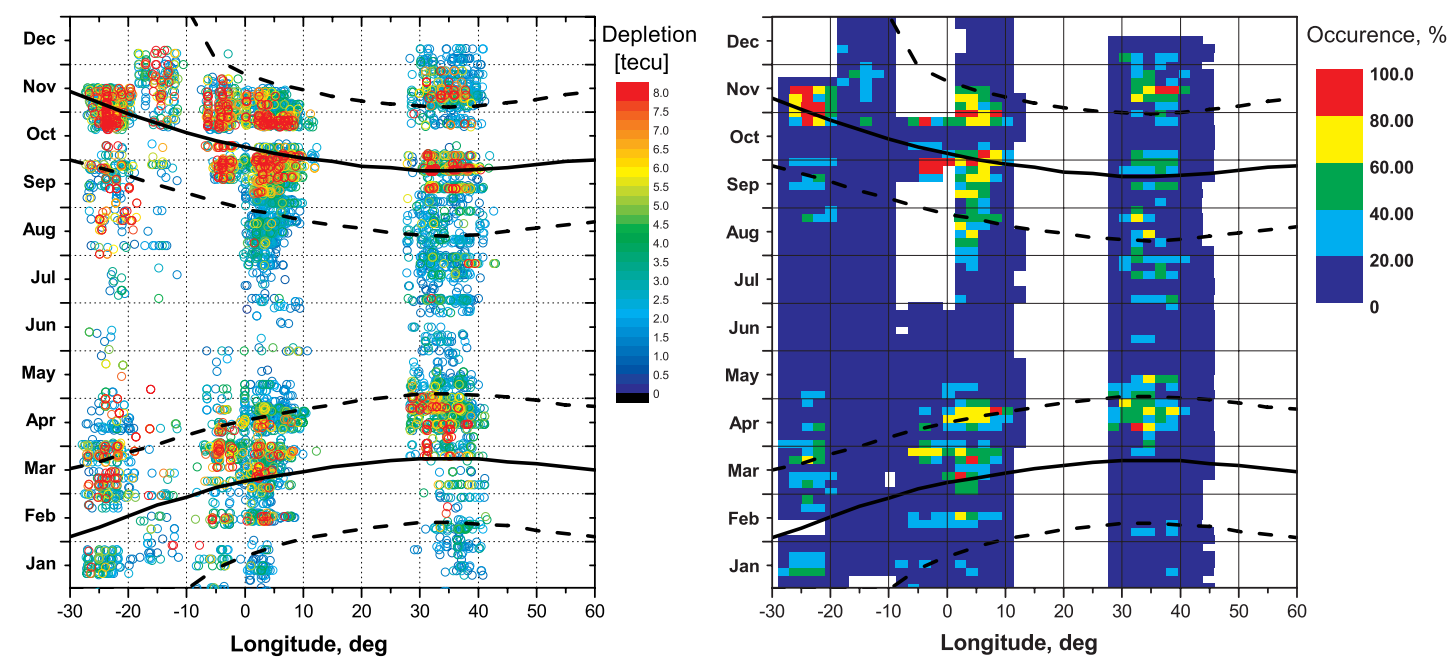

Fig. 5. Left panel: EPB intensity (TEC depletion depth in TECU) as a function of day of the year and longitude. Right panel: EPB occurrence rate. On the left panel all detected EPBs are shown, while on the right panel, data are binned in 5 degrees $\times 5$ day blocks, for which the occurrence rate is calculated. Black solid lines indicate the region where the solar terminator is best aligned with the local geomagnetic field. Black dashed lines indicate regions where this angle is equal to 15 degrees. The climatology of the EPBs overall is in agreement with that of the GPS scintillations shown in Fig. 4.

DMSP measurements, however were made during the solar maximum conditions (1999-2002), since during the solar minimum years there were just a few EPBs detected by the DMSP satellite. This difference is presumably attributed to the fact that during solar minimum conditions the plasma bubbles rarely reach the altitude of the satellite. In fact, this is one of the main advantages of the ground based technique, i.e., EPBs in the TEC measurements are more readily detected in comparison to the in-situ detection of EPB at $800 \mathrm{~km}$ (DMSP satellite orbit altitude), particularly during solar minimum.

Figure 5 suggests that the occurrence rate of EPBs during the boreal summer months increases with longitude from the Atlantic sector to the East Africa sector. Previous authors (Gentile et al., 2006; Stolle et al., 2006) also noted that the African longitude sector appears to have a higher occurrence rate of EPBs during the boreal summer months compared to any other longitude sector. A physical mechanism for this 


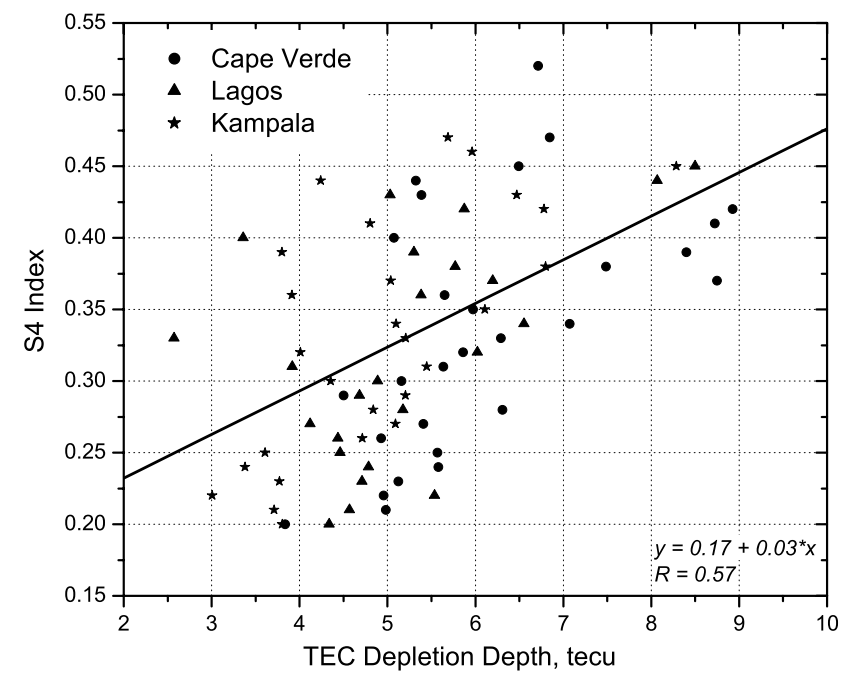

Fig. 6. Relation between the GPS scintillation intensity and TEC depletion depth (in TECU). Data from three stations Cape Verde, Lagos, and Kampala representing three regions are shown. A best linear fit line is shown with fit coefficients given in the lower right corner.

effect is not yet clear. As was mentioned in previous sections, two major factors are responsible for the spread-F climatology: the linear growth rate of the generalized RayleighTaylor instability and the presence of the seed perturbation. The first factor is mainly controlled by the ionospheric electrodynamics, while the seeding perturbations are typically attributed to the presence of medium scale gravity waves. It has been suggested by Tsunoda (2010a) that in the equatorial region, the seeding conditions for the gravity waves are determined by the position of the Intertropical Convergence Zone (ITCZ). It is perhaps not very likely, however, that there is a significant difference in the ITCZ location on such a scale (50-60 degrees of longitude). Other authors (E. Yizengaw, personal communication, 2010) have suggested there may be differences in the electrodynamical processes between the East and West coast of Africa, which could potentially explain the observed difference in EPB morphology derived from the TEC fluctuation measurements.

When comparing Fig. 5 and Fig. 4 one notices that GPS scintillations occur much more rarely during the summer time than the EPBs. This is especially evident for the East Africa region. This fact may be an indication that in the East Africa region the weak EPBs do not always evolve into the fully developed plumes with the associated small scale turbulent structure that cause GPS scintillations. A perhaps more likely possibility is that although plasma bubbles are present, the total integrated density fluctuation (which can be limited by the background plasma density) along the GPS raypath is insufficient to produce signal scintillations at the $\mathrm{L}$ band frequency. A quick examination of the vertical GPS TEC data over the SCINDA stations (not shown) did not reveal any significant differences in background electron density distribution over this relatively limited longitudinal extent, but this of course does not directly indicate the level of integrated density fluctuations present. It will be interesting to see whether boreal summer EPBs result in scintillations during the upcoming solar maximum, when the density depletions are likely to be deeper and the fluctuation level larger.

We analyzed the relationship between the depth of TEC depletion associated with plasma bubbles and corresponding GPS scintillation intensity. It is natural to expect that deeper depletions cause stronger scintillations, since the scintillation intensity is directly related to the electron density fluctuations $\Delta N$ along the GPS signal radiopath. These results are shown in Fig. 6, combining the data from three SCINDA stations: Cape Verde, Lagos, and Kampala (same as in Fig. 3) and representing three regions introduced in Fig. 1. For each station, S4 index data are binned with $0.01 \mathrm{step}$, and for each databin the median TEC depletion depth is determined for S4 index values greater than 0.2. Generally, the results show a clear linear dependence between the S4 index and depletion depth, although the spread of the data is rather significant $(R=0.57)$. The ratios between $\mathrm{S} 4$ index values and the depletion depth are very close for all three stations. Note that depletions with values smaller than 2 TEC units generally do not produce GPS scintillations. It is generally acknowledged that most of the scattering of L band signals occurs within a thin layer surrounding the peak of the F layer (Basu et al., 1983). Whalen (2009) suggested that while scintillations are associated with plasma bubbles, its strength is determined by the background electron density that the bubble intersects, presumably because a larger background density can admit larger density fluctuations. Therefore, it is expected that the correlation between the scintillation intensities and electron densities or electron density fluctuations measured near the peak of the F layer would be stronger than that between scintillation intensities and total TEC changes. In the current study, unfortunately, we did not have measurements of the ionosphere peak densities or fluctuations at the SCINDA stations (e.g., taken by ionosondes or radars). It should also be pointed out that during strong spread $\mathrm{F}$ conditions it is very difficult to make reliable measurements of the electron density profile with any of the existing ground-based methods. Thus the observed spread of the data in Fig. 6 should not be very surprising.

\section{Summary and conclusions}

In this paper we presented GPS TEC observations from new SCINDA network sites in equatorial Africa region. Most of these stations began their routine operations in 2009. The intensity of GPS signal scintillations is calculated by measuring the standard deviation of normalized GPS signal power. Because the measurements were made during very low solar activity conditions, the amplitudes of the observed 
scintillations were quite low. For this reason we decided to apply an additional filtering algorithm to separate the scintillation signals from local interference (multipath). We have also applied an automated technique to determine EPBs in GPS TEC observations. We have found a definite correlation between the depths of the TEC depletions and intensities of the corresponding scintillation.

Overall, the seasonal climatology of the EPBs as well as GPS scintillations is adequately explained by geometric arguments, i.e., the alignment of the solar terminator and local geomagnetic meridian, or STBA hypothesis (Tsunoda, 2010a). This is best illustrated with Figs. 4 and 5. The strongest and most frequent GPS scintillations as well as EPBs occur during the equinox periods in all three longitudinal sectors which were covered by the observations. Within the equinox periods, the most intense, longest lasting, and most frequent GPS scintillations and EPBs are observed in the Atlantic region. The observed longitudinal dependence is a very interesting result, since it also implies the longitudinal difference in the value of the pre-reversal enhancement (PRE) of the $\boldsymbol{E} \times \boldsymbol{B}$ drift velocity after sunset. We note that the East African sector around $40^{\circ} \mathrm{E}$ (geographic) is located near the boundary of the 4-cell non-migrating tidal structure which was discovered recently from satellite observations (Immel et al., 2006; Anderson et al., 2009). It is plausible to suggest that the PRE value at the cell boundary could be lower than that in the middle of the cells. Overall, these findings need further analysis with more long-term observations. In Africa, especially in the East Africa region, the shallower EPBs are observed practically all year long, even during the boreal summer solstice. This result is consistent with DMSP data observations in this region made during solar maximum conditions (Gentile et al., 2006). During the boreal summer time the presence of GPS scintillations appears to be not very significant in this region, at least for the level of solar activity observed in 2010. Generally, in our study we observed that EPBs with depletion depth smaller than 2 TEC units rarely produce scintillations. It will be interesting to see whether boreal summer EPBs result in scintillations during the upcoming solar maximum, when the density depletions are likely to be deeper and the fluctuation level larger. To investigate this further it would be advantageous to have electron density profile measurements, (e.g., with ionosonde or COSMIC data) in order to be able to obtain the full integrated electron density fluctuations along the GPS signal radiopath.

The major question our study raises is what mechanism is responsible for the important transition in the occurrence phenomenology of EPBs and GPS scintillations that occurs between the Atlantic region and East Africa? This is a relatively small region, and, therefore, it seems unlikely that the spread-F seeding conditions could be significantly different on such a scale. Possible difference in the ionospheric electrodynamics appears to be a more likely candidate. More data is needed for further investigation of the distributions of the EPBs and GPS scintillations in African equatorial region and for in-depth study of their relation.

The SCINDA network in the African continent is expanded with the help of many international partners, making it possible to study the unique behavior of the equatorial ionosphere over Africa. We hope to ensure global coverage in time for the upcoming solar maximum. AFRL has deployed three additional GPS receivers in the Congo region to help with coverage in Central Africa. At least a few additional sites are still needed, however, especially in the northern anomaly region.

Acknowledgements. The authors are grateful to have received support from AFOSR for this work.

Topical Editor K. Kauristie thanks two anonymous referees for their help in evaluating this paper.

\section{References}

Aarons, J.: The longitudinal morphology of equatorial F layer irregularities relevant to their occurrence, Space Sci. Rev., 63, 209243, 1993.

Abdu, M. A., Batista, I. S., Reinisch, B. W., de Souza, J. R., Sobral, J. H. A., Pedersen, T. R., Medeiros, A. F., Schuch, N. J., de Paula, E. R., and Groves, K. M.: Conjugate Point Equatorial Experiment (COPEX) campaign in Brazil: Electrodynamics highlights on spread F development conditions and day-to-day variability, J. Geophys. Res., 114, A04308, doi:10.1029/2008JA013749, 2009.

Anderson, D., Araujo-Pradere, E., and Scherliess, L.: Comparing daytime, equatorial $\boldsymbol{E} \times \boldsymbol{B}$ drift velocities and TOPEX/TEC observations associated with the 4-cell, non-migrating tidal structure, Ann. Geophys., 27, 2861-2867, doi:10.5194/angeo-272861-2009, 2009.

Basu, S., Basu, Su., McClure, J. P., Hanson, W. B., and Whitney, H. E.: High resolution topside in situ data of electron densities and VHF/GHz scintillations in the equatorial region, J. Geophys. Res., 88, 403-415, doi:10.1029/JA088iA01p00403, 1983.

Burke, W. J., Gentile, L. C., Huang, C. Y., Valladares, C. E., and $\mathrm{Su}, \mathrm{S}$. Y.: Longitudinal variability of equatorial plasma bubbles observed by DMSP and ROCSAT-1, J. Geophys. Res., 109, A12301, doi:10.1029/2004JA010583, 2004.

Calvert, W. and Cohen, R.: The Interpretation and Synthesis of Certain Spread- $F$ Configurations Appearing on Equatorial Ionograms, J. Geophys. Res., 66, 3125-3140, doi:10.1029/JZ066i010p03125, 1961.

Carrano, C. S. and Groves, K.: The GPS Segment of the AFRLSCINDA Global Network and the Challenges of Real-Time TEC Estimation in the Equatorial Ionosphere, Proceedings of the 2006 National Technical Meeting of The Institute of Navigation, Monterey, CA, January 2006, pp. 1036-1047, 2006.

Carrano, C. S. and Groves, K. M.: Temporal decorrelation of GPS satellite signals due to multiple scattering from ionospheric irregularities, Proceedings of the 2010 Institute of Navigation ION GNSS meeting, Portland, OR, 21-24 September 2010.

Datta-Barua, S., Doherty, P. H., Delay, S. H., Dehel, T., and Klobuchar, J. A.: Ionospheric Scintillation Effects on Single and Dual Frequency GPS Positioning, Proceedings of the 16th International Technical Meeting of the Satellite Division of The 
Institute of Navigation (ION GPS/GNSS 2003), Portland, OR, September 2003, 336-346, 2010.

Farley, D. T., Balsey, B. B., Woodman, R. F., and McClure, J. P.: Equatorial Spread $F$ : Implications of VHF Radar Observations, J. Geophys. Res., 75, 7199-7216, doi:10.1029/JA075i034p07199, 1970.

Gentile, L. C., Burke, W. J., and Rich, F. J.: A global climatology for equatorial plasma bubbles in the topside ionosphere, Ann. Geophys., 24, 163-172, doi:10.5194/angeo-24-163-2006, 2006.

Groves, K. M., Basu, S., Weber, E. J., Smitham, M., Kuenzler, H., Valladares, C. E., Sheehan, R., MacKenzie, E., Secan, J. A., Ning, P., McNeill, W. J., Moonan, D. W., and Kendra, M. J.: Equatorial scintillation and systems support, Radio Sci., 32, 2047-2064, 1997.

Hei, M. A., Heelis, R. A., and McClure, J. P.: Seasonal and longitudinal variation of large-scale topside equatorial plasma depletions, J. Geophys. Res., 110, A12315, doi:10.1029/2005JA011153, 2005.

Huang, C. Y., Burke, W. J., Machuzak, J. S., Gentile, L. C., and Sultan, P. J.: Equatorial plasma bubbles observed by DMSP satellites during a full solar cycle: Toward a global climatology, J. Geophys. Res., 107, 1434, doi:10.1029/2002JA009452, 2002.

Hysell, D. L. and Kudeki, E.: Collisional shear instability in the equatorial $F$ region ionosphere, J. Geophys. Res., 109, A11301, doi:10.1029/2004JA010636, 2004.

Hysell, D., Kelley, M., Swartz, W., and Woodman, R.: Seeding and layering of equatorial spread $\mathrm{f}$ by gravity waves, J. Geophys. Res., 95, A10, doi:10.1029/JA095iA10p17253, 1990.

Immel, T. J., Sagawa, E., England, S. L., Henderson, S. B., Hagan, M. E., Mende, S. B., Frey, H. U., Swenson, C. M., and Paxton, L. J.: Control of equatorial ionospheric morphology by atmospheric tides, Geophys. Res. Lett., 33, L15108, doi:10.1029/2006GL026161, 2006.

McClure, J., Singh, S., Bamgboye, D., Johnson, F., and Kil, H.: Occurrence of equatorial $\mathrm{F}$ region irregularities: Evidence for tropospheric seeding, J. Geophys. Res., 103, 29119-29135, 1998.

Retterer, J. M. and Gentile, L. C.: Modeling the climatology of equatorial plasma bubbles observed by DMSP, Radio Sci., 44, RS0A31, doi:10.1029/2008RS004057, 2009.

Secan, J. A., Bussey, R. M., Fremouw, E. J., and Basu, Sa.: An improved model of equatorial scintillation, Radio Sci., 30, 607617,1995
Seemala, G. K. and Valladares, C. E.: Statistics of TEC depletions observed over the South American continent for the year 2008, Radio Sci., 46, RS5019, doi:10.1029/2011RS004722, 2011.

Stolle, C., Lühr, H., Rother, M., and Balasis, G.: Magnetic signatures of equatorial spread $F$ as observed by the CHAMP satellite, J. Geophys. Res., 111, A02304, doi:10.1029/2005JA011184, 2006.

Sultan, P. J.: Linear theory and modeling of the Rayleigh-Taylor instability leading to the occurrence of equatorial spread F, J. Geophys. Res., 101, 26875-26891, doi:10.1029/96JA00682, 1996.

Tsunoda, R. T.: Control of the seasonal and longitudinal occurrence of equatorial scintillations by the longitudinal gradient in integrated E region Pedersen conductivity, J. Geophys. Res., 90, 447-456, 1985.

Tsunoda, R. T.: On seeding equatorial spread $\mathrm{F}$ during solstices, Geophys. Res. Lett., 37, L05102, doi:10.1029/2010GL042576, 2010a.

Tsunoda, R. T.: On equatorial spread $F$ : Establishing a seeding hypothesis, J. Geophys. Res., 115, A12303, doi:10.1029/2010JA015564, 2010b.

Valladares, C. E. and Doherty, P. H.: The Low-Latitude Ionosphere Sensor Network (LISN), Proceedings of the 2009 International Technical Meeting of The Institute of Navigation, Anaheim, CA, January 2009, pp. 16-24, 2009.

Valladares, C. E., Hanson, W. B., McClure, J. P., and Cragin, B. L.: Bottomside sinusoidal irregularities in the equatorial $\mathrm{F}$ region, J. Geophys. Res., 88, 8025-8042, 1983.

Whalen, J.: An equatorial bubble: Its evolution observed in relation to bottomside spread $\mathrm{F}$ and to the Appleton anomaly, J. Geophys. Res., 105, 5303-5315, 2000.

Whalen, J. A.: The linear dependence of GHz scintillation on electron density observed in the equatorial anomaly, Ann. Geophys., 27, 1755-1761, doi:10.5194/angeo-27-1755-2009, 2009.

Wiens, R. H., Ledvina, B. M., Kintner, P. M., Afewerki, M., and Mulugheta, Z.: Equatorial plasma bubbles in the ionosphere over Eritrea: occurrence and drift speed, Ann. Geophys., 24, 14431453, doi:10.5194/angeo-24-1443-2006, 2006.

Woodman, R. F. and La Hoz, C.: Radar Observations of F Region Equatorial Irregularities, J. Geophys. Res., 81, 5447-5466, 1976. 